\title{
Knowledge of the Covid-19 Virus, From Diagnosis to Prevention and Treatment: A Narrative Review
}

Jahanpeyma. $\mathrm{P}^{1}$

*Shamsi. A $^{2}$

Nejad Rahim. $\mathrm{R}^{3}$

Aghazadeh Sarhangipour. $\mathrm{K}^{4}$

1- Ph.D. of Nursing, Assistant Professor, Faculty of Nursing and Midwifery, Urmia University of Medical Sciences, Urmia, Iran.

2- ( ${ }^{*}$ Corresponding Author) Post Ph.D. of Palliative and Protective Care, Assistant Professor, Faculty of Allied Medicine, Tehran University of Medical Sciences, Tehran, Iran. Nursing and Midwifery Care Research Center, Tehran University of Medical Sciences, Tehran, Iran.

Email:Afzal_sh63@yahoo.com

3- MD, Infectious Disease

Associate Professor, Dermatology and Infectious Diseases Department, Urmia University of Medical Sciences, Urmia, Iran

4- MD, Infectious Diseases, Assistant Professor, Infection Research Center, Infectious Diseases Department, Faculty of Medicine, Aja University of Medical Sciences, Tehran, Iran.

\section{Abstract}

Introduction: Coronavirus or Covid-19 is a type of acute respiratory syndrome caused by a virus from the corona family of viruses that have affected all countries in the world in a short period. Familiarity and introduction of Covid-19 virus is very important due to the prevalence and high mortality rate of this disease, as well as the possibility of recurrence of Covid-19, especially in autumn, and the lack of vaccines or specific treatment.

Objective: The aim of this study was "Introduction to Covid-19 virus in terms of diagnosis, prevention and treatment"

Material and Methods: In this study, researchers did a survey of search engine such as Google Scholar, Google, PubMed databases, Science Direct and CDC and WHO sites in 2019 and 2020, related to the purpose of the study (in "Persian" and "English").

Results: In the present study, diagnosis, treatment programs, prevention and control of disease was done using updated data on Covid-19 virus, epidemiology of disease, structure, and source of the virus, disease symptoms and routes of transmission.,. The diagnosis of this virus, besides its clinical signs, relies on laboratory and radiological findings. Any specific drug treatment will not be introduced for Covid-19 until June 30,2020 , so the best way in the current situation is to prevent the disease.

Discussion and Conclusion: Due to the momentary increase in patients with Covid-19 and its high mortality, lack of vaccines and definitive drug treatment, it is recommended that people apply the correct health principles, and observe the social sdistances. To prevent and manage the recurrence of Covid-19 in the fall, it is an undeniable necessity to develop and implement comprehensive and infrastructural programs immediately. Is an.

Keywords: Corona, Covid-19, Diagnosis, Pandemic, Prevention, Treatment. 


\title{
دانستنىهاى ويروس كوويد 19، از تشخيص تا يشكَيرى و درمان: يك مرور روايتى
}

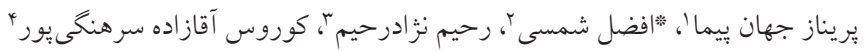

جكيده

مقدمه: ويروس كرونا يا كوويد -19 يك نوع سندرم تنفسى حاد با عامل ويروسى از خانواده كرونا ويروسها مىباشد كه همه كشورهاى جهان را در مدت زمان كوتاهى دركير كرده است. با توجه به شيوع و ميزان مرك و مير بالاى اين بيمارى لرى

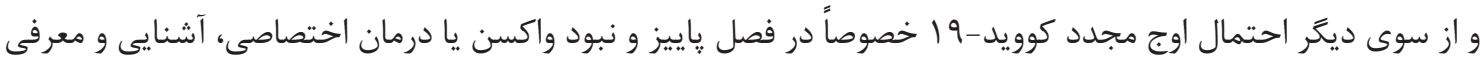

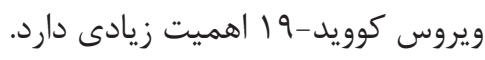

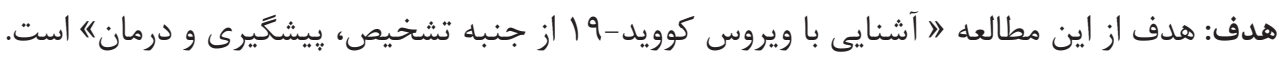

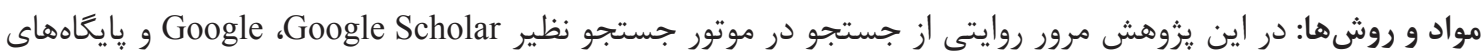

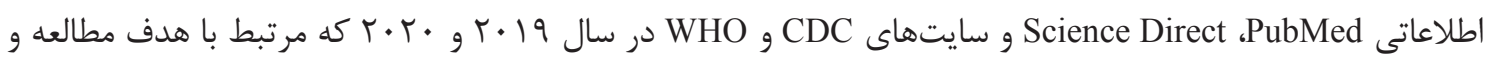
به زبان " فارسى" و " انخليسى" بودند استفاده شد.

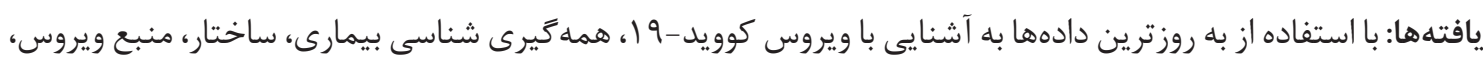

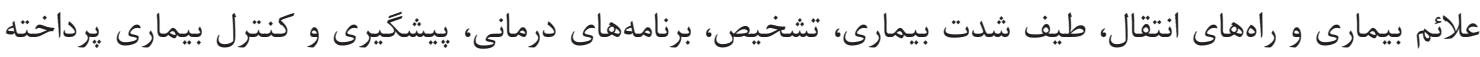

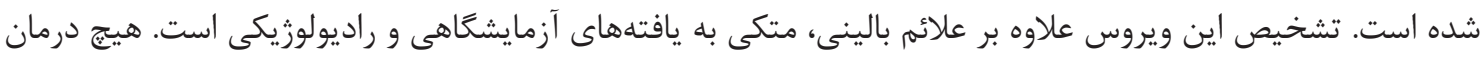

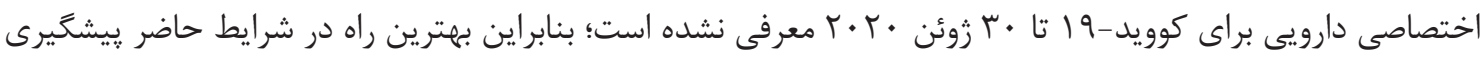
از بيمارى مىباشد. بحث و نتيجهَيرى: با توجه به افزايش لحظهاى مبتلايان به كوويد-19 و ورك و و مير بالاى ناشى از آن، نبود واكسن و

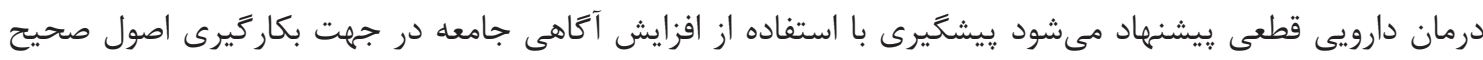
بهداشتى، رعايت فاصله اجتماعى و نظارت دقيق بر اجراى صحيح آنها انجام كيرد. تدوين و اجراى فورى برنامههاى جامع و زيربنايى جهت بِيشكيرى و مديريت شيوع مجدد كوويد-9 ا در فصل باييز ضرورتى انكار نايذير است.

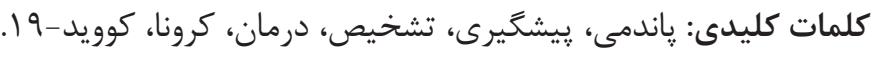

\begin{tabular}{|c|c|c|}
\hline १щ & 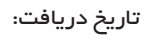 & 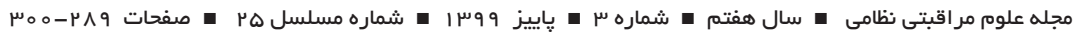 \\
\hline १щq৭/К/ץн & 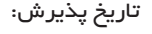 & \\
\hline १щ११/१/щ。 & ت ت اريخ انتشار: & \\
\hline
\end{tabular}

حاضر در سراسر جهان گسترش يافته و روزانه تعداد زيادى از مقلمهـ

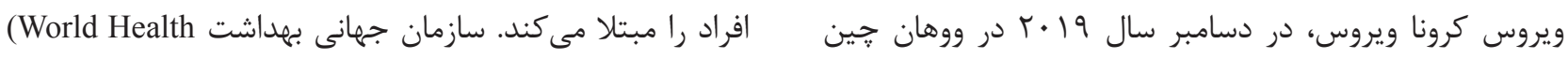
Organization) يديدار شد. اين بيمارى يك نوع سندرم تنفسى حاد (ينومونى دمانى

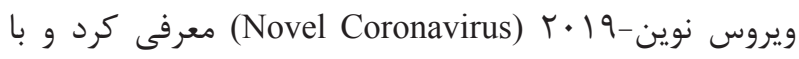

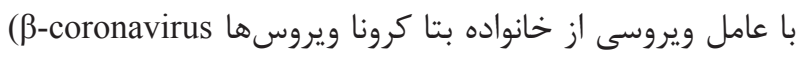
مع or Beta Coronavirus) 
جهانى بهداشت، مركز كنترل و يیشخَيرى بيمارى، وزارت بهداشت، درمان و آموزش يزشكى ايران نيز استفاده شد.

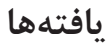

\section{همد}

كوويد-9 19 يك بيمارى جديد است. شيوع اين بيمارى ما را به يه ياد شيوع (Severe Acute Respiratory Syndrome Coronavirus) (Middle East Respiratory Syndrome g بر سال r... Coronavirus)

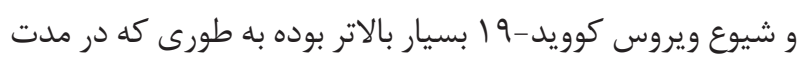

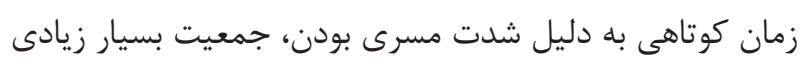

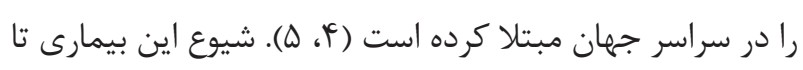

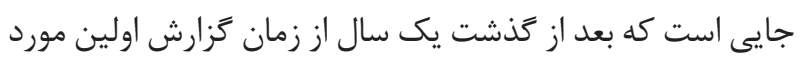

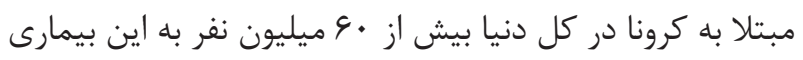

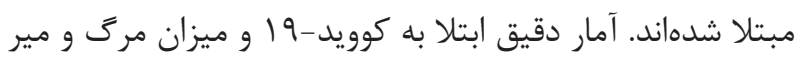

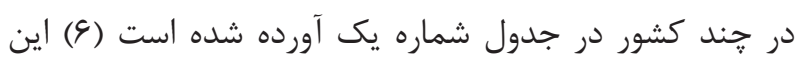

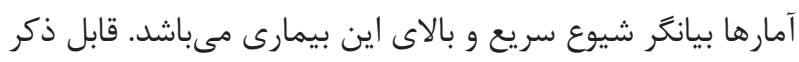
است كه اين آمار هر ساعت با شيوع بالايى رو به افزايش است.

\section{ساختار ويروس كوويد-19 - س}

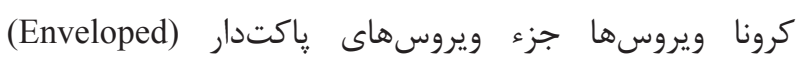

جدول ا- ميزان شيوع بيمارى كوويد-19 و مركى و مير ناشى از آن در برخى از

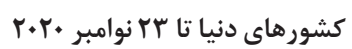

\begin{tabular}{|c|c|c|c|}
\hline بهببوديافتخان & فوت شدكان & مبتلايان & نام كشور \\
\hline$V / \& \Delta T / \varepsilon / \&$ & TGT/V.I & $\mid r / \Delta \wedge q / \cdot \wedge \Lambda$ & آمر يكا \\
\hline$N / D G Y / G F \mid$ & ITr/VVR & $q / I F \cdot / r / r$ & هند \\
\hline$\Delta / \mathcal{F} T / \Delta \cdot \Delta$ & $199 / 197$ & $G / \cdot V \mid / 4 \cdot 1$ & برزيل \\
\hline$|\& q / \Delta T|$ & FA/VYT & $r / / F \cdot / r \cdot \Lambda$ & فرانسه \\
\hline $1 / 911 / 44 \Delta$ & rG/QT. & $r / l / r / \Delta \cdot r$ & روسيه \\
\hline كزارش نشده & Fr/919 & $1 / 0 \wedge 9 / \pi / 9$ & اسپيانيا \\
\hline كزارش نشده & $\Delta \Delta / \cdot T^{F}$ & $1 / Q 1 Y / \cdot Y \Delta$ & انغلستان \\
\hline$\Delta \Delta r / \cdot 9 \Lambda$ & Fq/Arr & $1 / 4 \cdot \Lambda / \wedge \& \Lambda$ & ايتاليا \\
\hline $1 / 19 \Delta / 49 T$ & $r V / \cdot \cdot r$ & $1 / \pi V \cdot / r q 4$ & آرزانتين \\
\hline $1 / 10 \cdot / q \pi T$ & $r \Delta / r \wedge V$ & I/TFN/FIV & كلمبيا \\
\hline G. T/FYD & $r \xi \lambda \cdot r$ & $\Lambda \Delta F / Y G \mid$ & ايران \\
\hline
\end{tabular}

رسماً كوويد-19 (COVID-19) نامكذارى كرد (1). WHO در

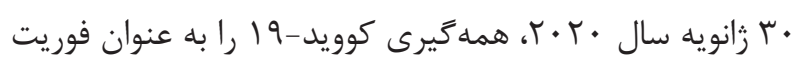
بهداشت عمومى با نكر انى بين المللى Publi Health Emergency) of InteRNAtional Concern) بسيار بالاى اين بيمارى در سراسر كشورهاى دنيا، در تاريخ 11

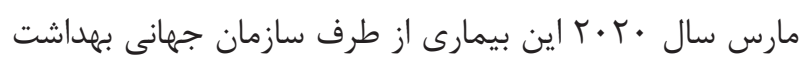

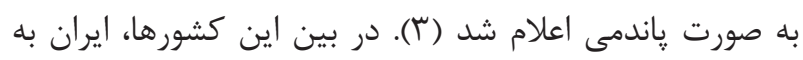

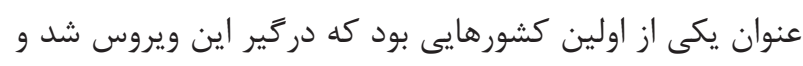

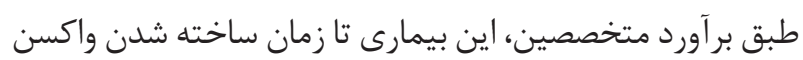

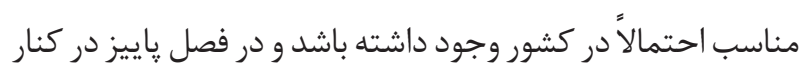
آنفولانزا، شيوع مجدد داشته باشد. با توجه به اهميت كوويد

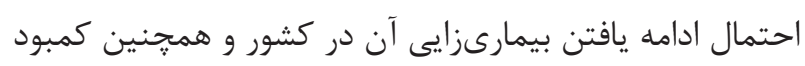

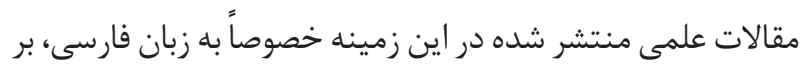
آن شديم تا انجام تحقيقى با هدف " آشنايى با ويروس كوويد-19 19

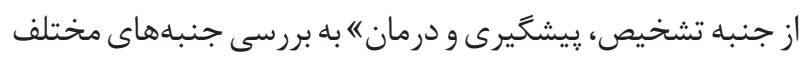
اين بيمارى بيردازيم.

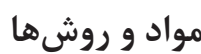

اين مقاله حاصل يك يزوهش مرورى روايتى است كه با جستجو

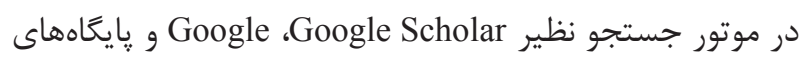

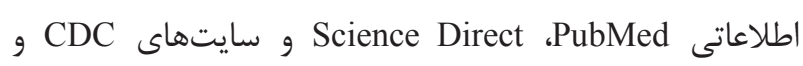
WHO

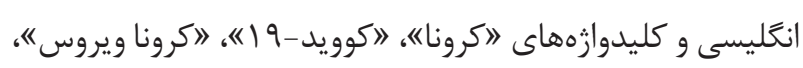
د «COVID-19》، «Coronavirus»، «Novel Coronavirus»

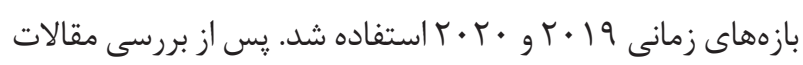

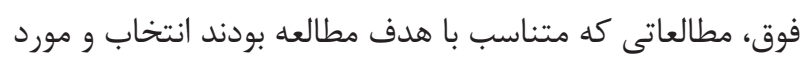

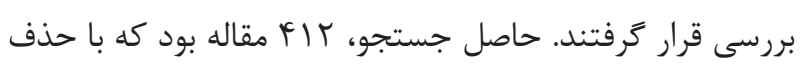
موارد تكرارى و مقالات فاقد متن كامل (مقالاتى كه در زورنال هاى جندي

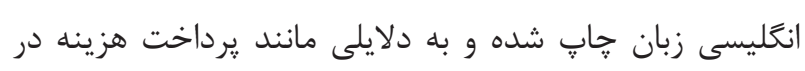

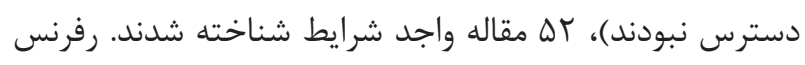

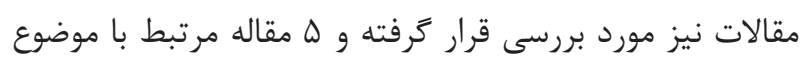

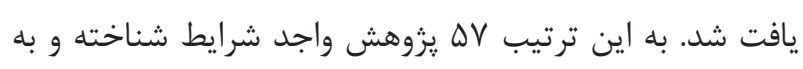

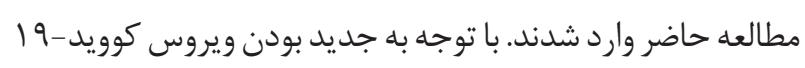

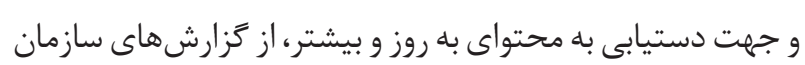


اوليه حيوانى دارد (1 (1). آناليز فيلوزنتيكى (Phylogenetic) نشان

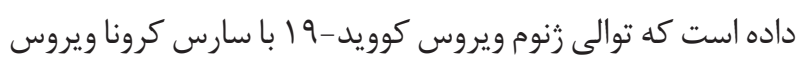

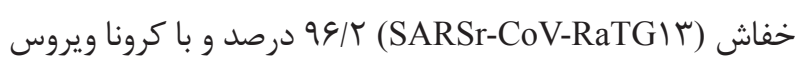

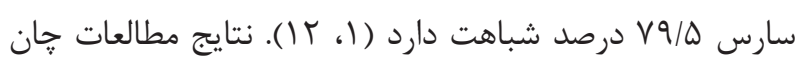
(Chan)

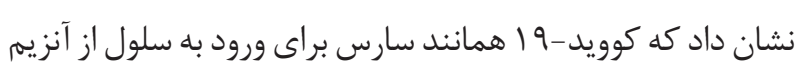

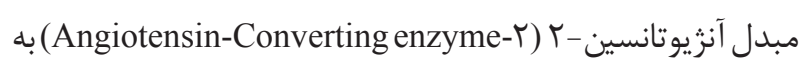

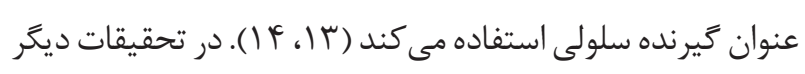
نيز بر اساس نتايج تعيين توالى زنوم ويروس و تجزيه و تحليل نايل

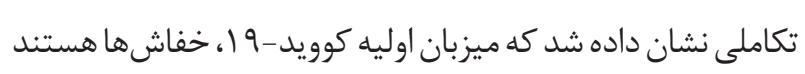
و در ادامه، اين ويروس وارد يك ميزبان حدواسط مورجه خوار شده دهان

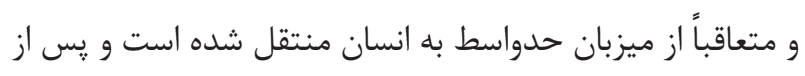

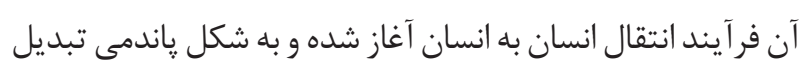

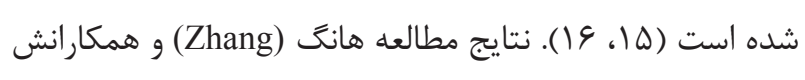
نيز نشان مى دهد كه توالى زنوم ويروس و تجزيه و تحليل تكاملى

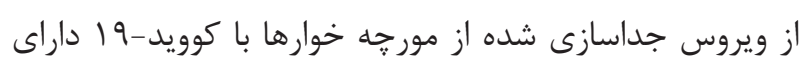

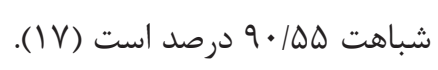

\section{علائم و راههاى انتقال بيمارى كوويد 19} بر اساس گزارش مركز كنترل و پيشگَيرى بيمارى، علائم

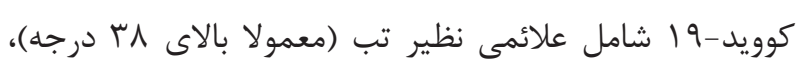
سرفه، تنكى نفس يا مشكل در تنفس، لرز، تكانهاى مكرر همراه

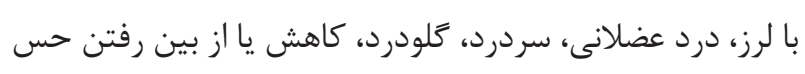

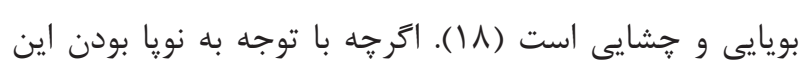

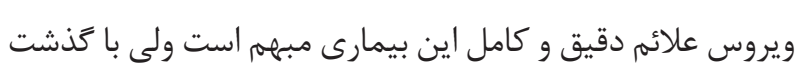

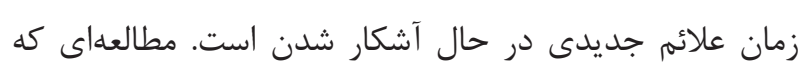

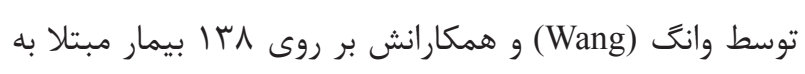

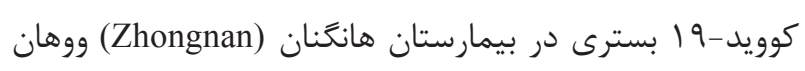

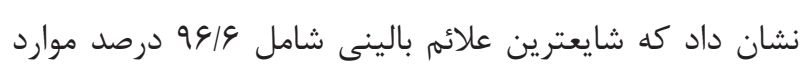

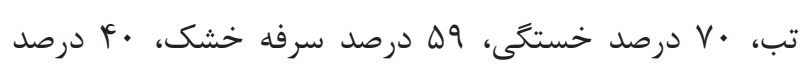

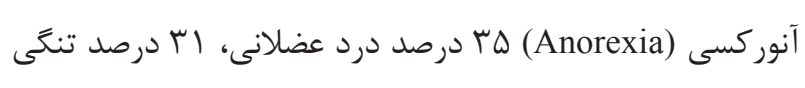

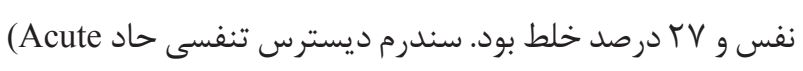
Respiratory Distress Syndrome)

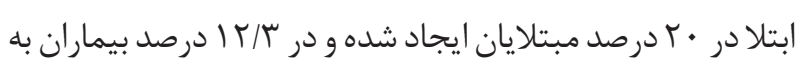

بدون تقسيم (Non-Segmented)، داراى ريبونوكلوئيك اسيد (Positive- تك رشتهاى با پلاريته مثبت داري ريونويك (Ribonucleic Acid)

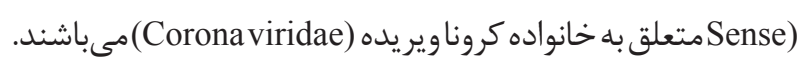

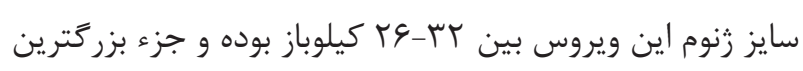

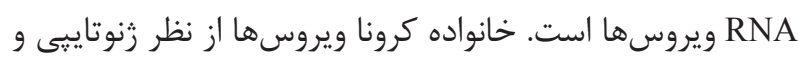

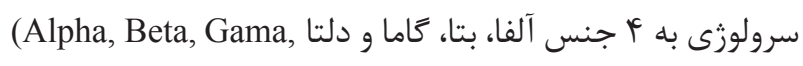
Delta OR $\alpha, \beta, \gamma, \delta$ ) جنس آلفا و بتا عمدتاً ٍِتانداران را آلوده كرده و بيمارى نهاى

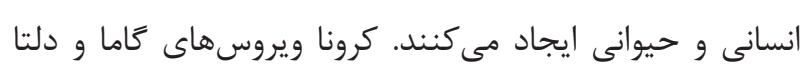
بيشتر در يرند كان ديده مىشود (1، (V).

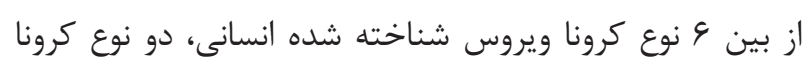

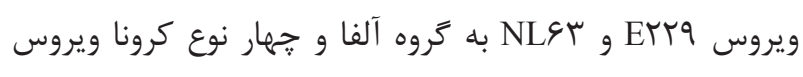

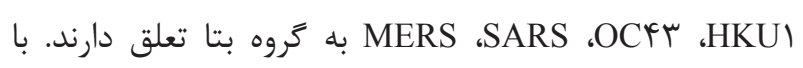

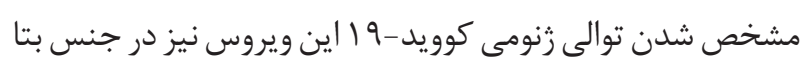

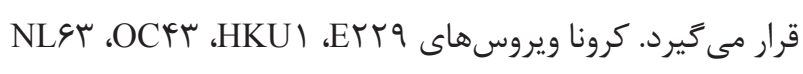
با قدرت بيمارىزايى كم باعث علائم خفيف شبه سرماخوردى كرونى

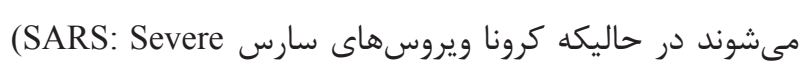
(MERS: Middle East و و مرس سارس (Scute Respiratory Syndrome) Respiratory Syndrome Virus) شديد و بالقوه كشنده دستكاه تنفسى مىشود (^).

\section{منبع بيمارى كوويد-19}

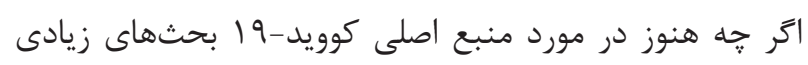

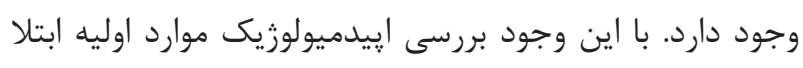

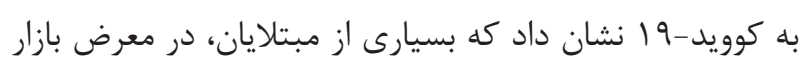

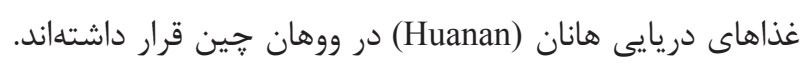

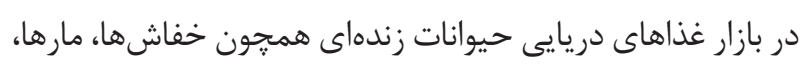
يرند انان، قورباغهها، جوجه تيغى و سايرحيوانات حيات وحش رئر رانيز

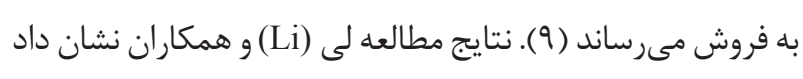
كه هه درصد مبتلايان به بازار غذاهاى دريايى هانان مرتبط بودند

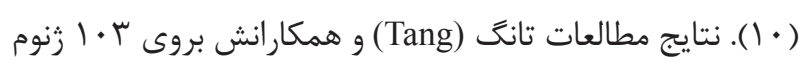

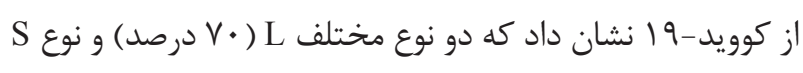

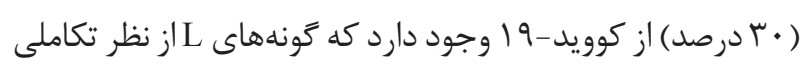
تهاجمىتر و مسرىتر هستند اين بيانكر آنست اين ويروس منشاء 


\section{طيف شدت بيمارى كوويد 19} طيف شدت بيمارى كوويد-19 از ناقلين بدون علامت تاديمارى

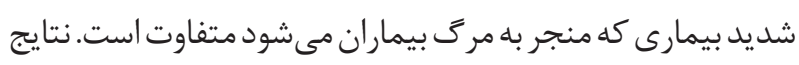

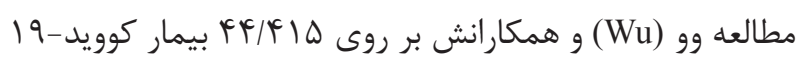

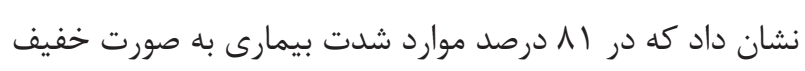

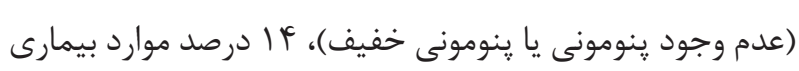

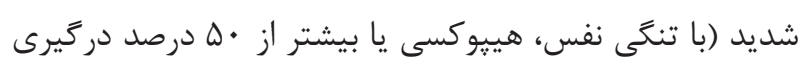

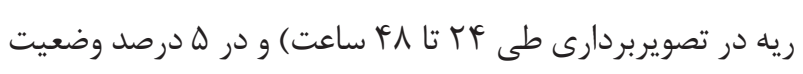
بحرانى (با نارسايى تنفسى، شوك سيتيك، يا اختلال عملكرد

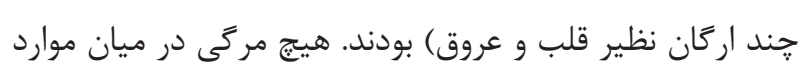

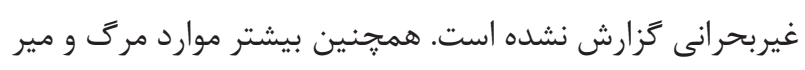

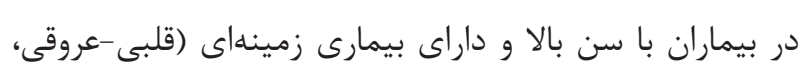

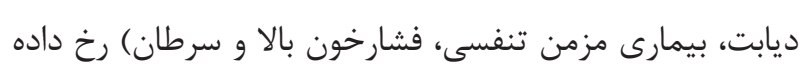

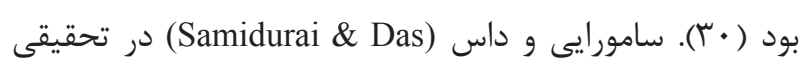

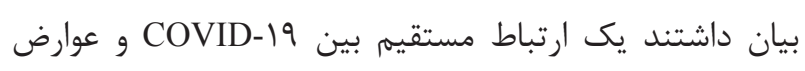

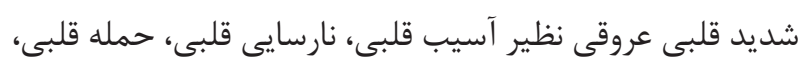

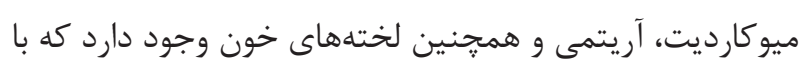
افزايش نتايج نامطلوب در ميان بيمار ان و حتى مركى ناگمهانى همراه

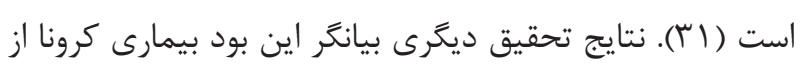

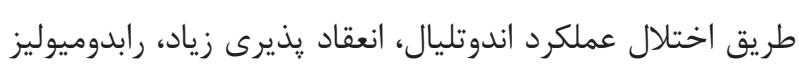
(Rhabdomyolysis) باعث مشكلات كليوى در بيماران مىشود (rr).

\section{تشخيص بيمارى كوويد-19}

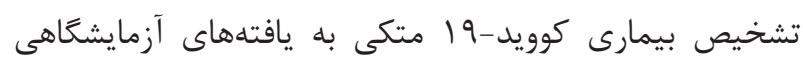

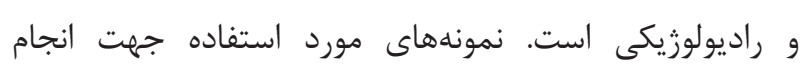
تست آزمايشگاهى شامل نمونههاى سواب نازوفارنزيال، خلط

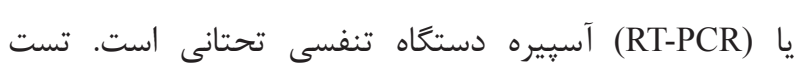

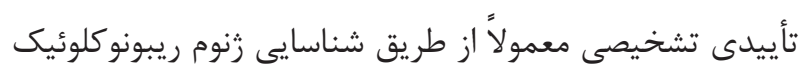

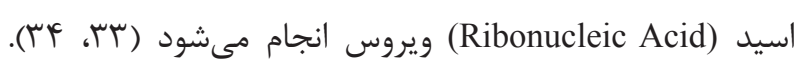

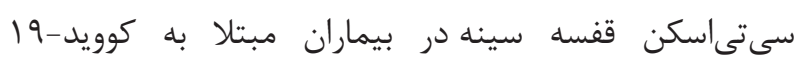

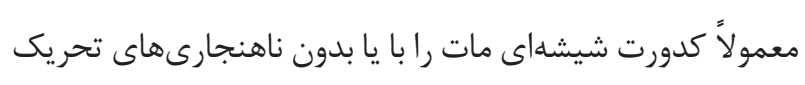

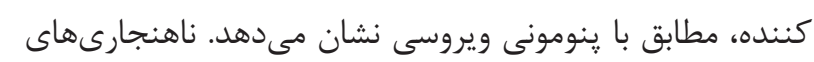

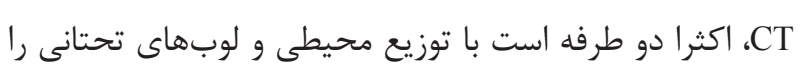

تهويه مكانيكى نياز شده است. همجنين در يافته هاى آزمايشكاهى

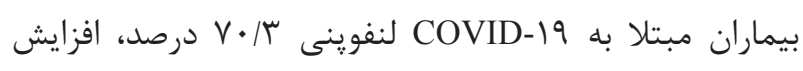
زمان :روترومبين (PT) ه د درصد، افزايش لاكتات دهيدروزناز 9/9 (Lactate Dehydrogenase)

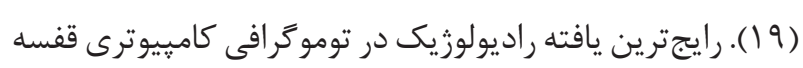

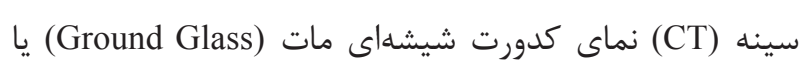
سايه تكه تكه (Patchy) دو طرفه بود (·) (Y). در اكثر مطالعات

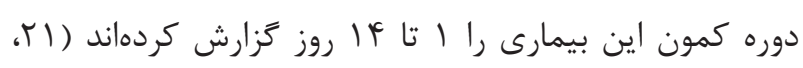
ST

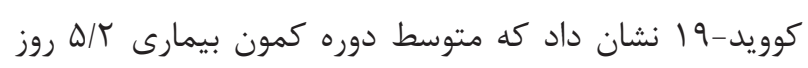

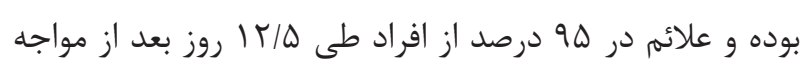
بروز مى كند (•) - (1). راههاى انتقال كوويد-9 1 به صورت فرد به فرد و عمدتاً از طريق تماس نزديك (شش فوت، حدود دو متر) و استنشاق قطرات

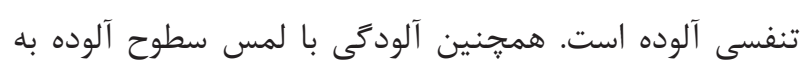

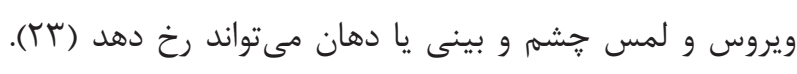

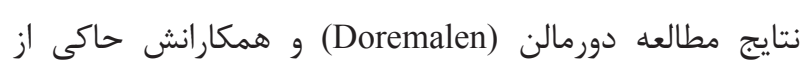

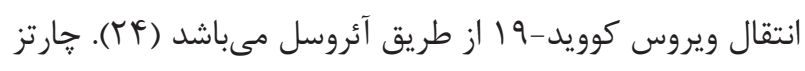

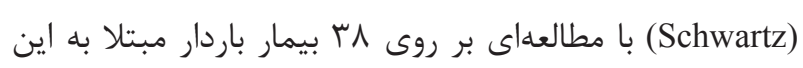

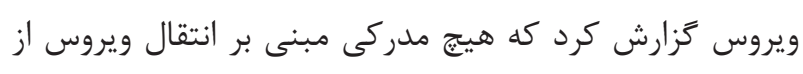

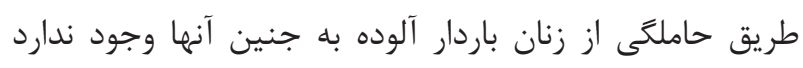

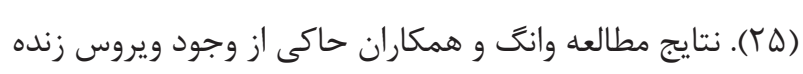

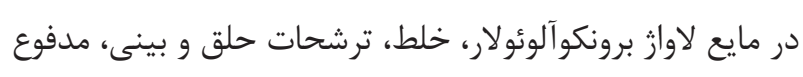

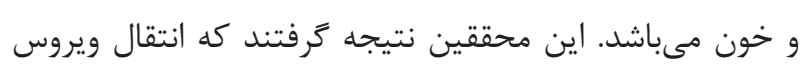
توسط دستكاه تنفسى و غير تنفسى ممكن است علت گسترش

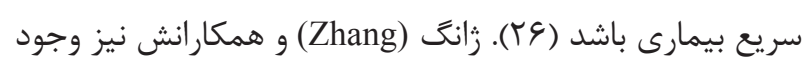

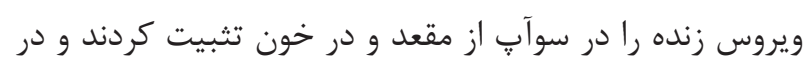

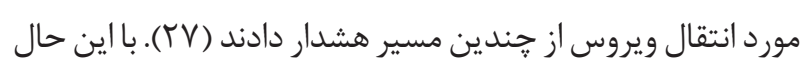
بر اساس كزارش سازمان جهانى بهداشت از بيماران جينى، انتقال مدفوعى - دهانى عامل مهمى در شيوع اين ويروس نمى باشد (Y) (Y).

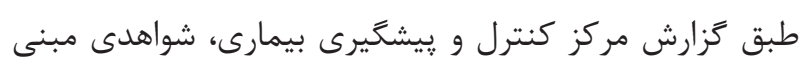

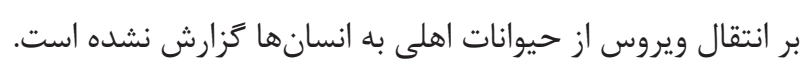

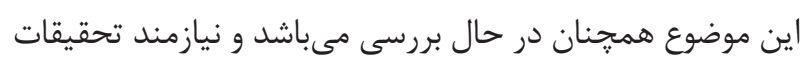

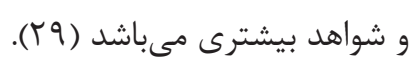




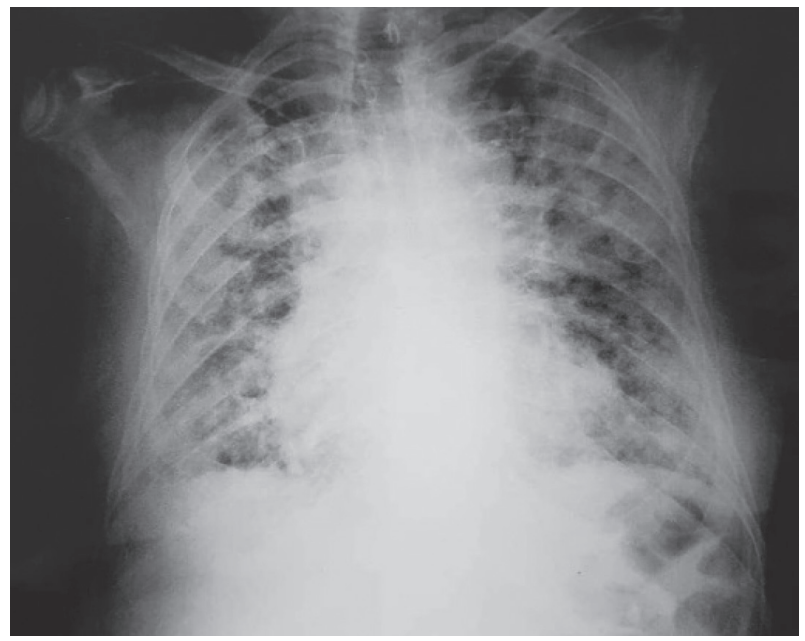

شكل 1 - كرافى قفسه سينه بيمار مبتلا به كوويد-19

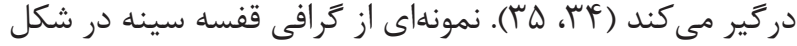
شماره ا و سى تى اسكن ريه در شكل شماره با آورده شده است.

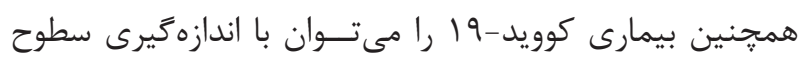

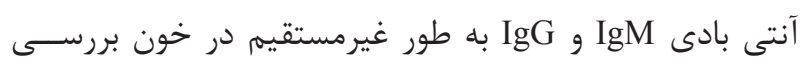

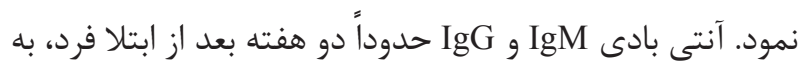
بالاترين سطح خود در خون مىرسد. كيتهاى هاى آنتى بادى IgG و IgM تشخيص بيمارى كوويد-9 19 دارند (צس).

برنامههاى درمانى بيمارى كوويد 19

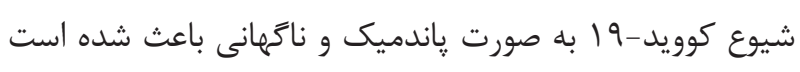

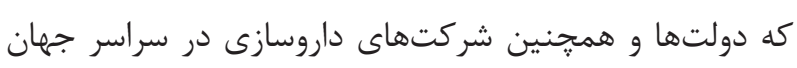

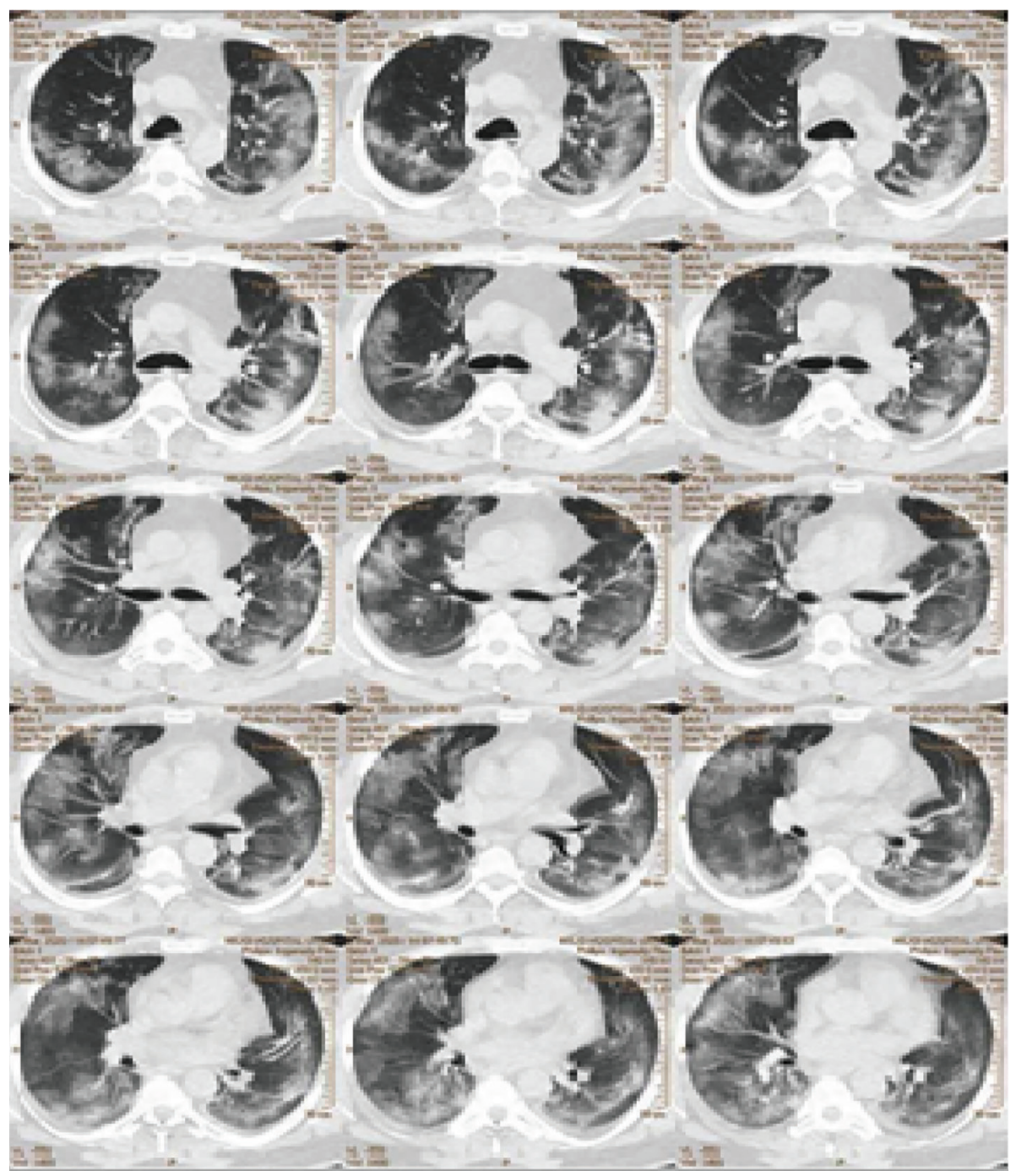

شكل r- سى تى اسكن بيمار مبتلا به كوويد-19 
به كوويد-19 آغاز شده است. جهت تعيين ايمنى و اثربخشى

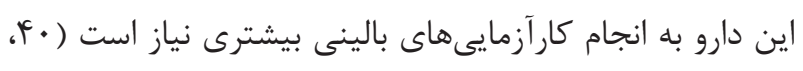

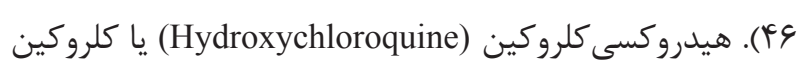

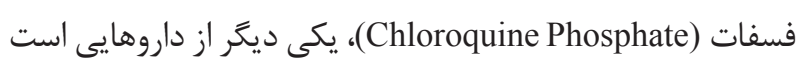
كه نتايج خوبى راعليه ينومونى كوويد-9 19 در مطالعات بالينى انجام

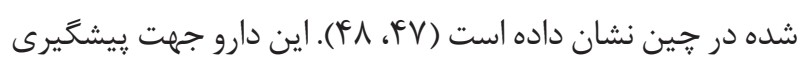

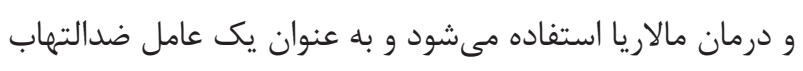

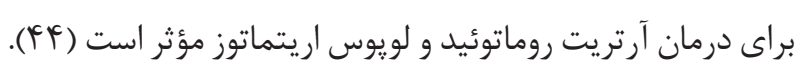

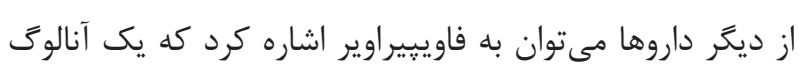

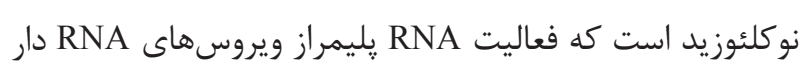

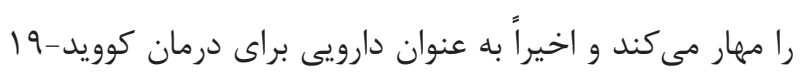

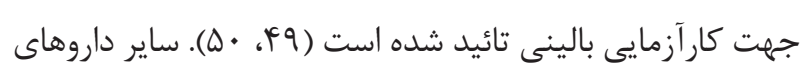
ضد ويروسى كه جهت درمان كوويد-19 الدر حال ارزيابى هستند

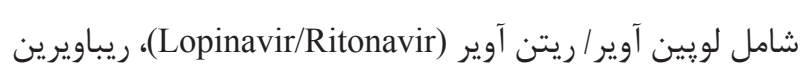

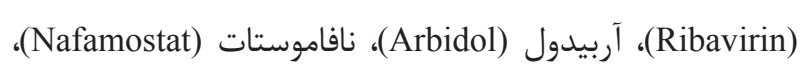

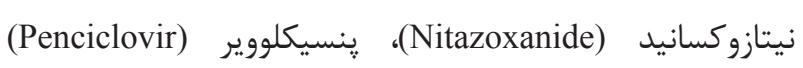
مىباشند كه در مراحل آزمايشخاهى نتايج خوبى را نشان دادند

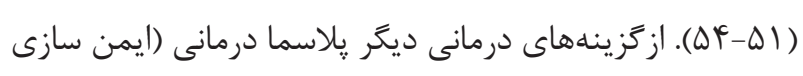

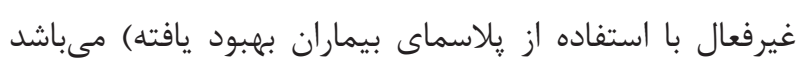

نتايج مطالعات متعدد نشان مى دهد كه آنتى بادىهاى ضدويروسى ) IgD و IgE ،IgM ،IgA ،IgG يافته داراى تأثيرات موثرى در عفونتهاى ويروسى و بيمارىهاى

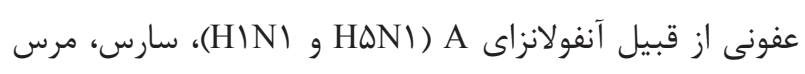

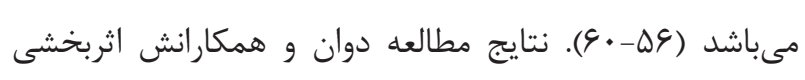

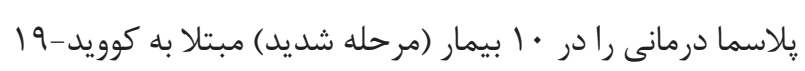

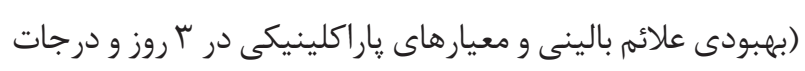

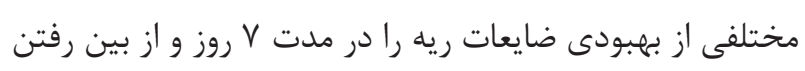

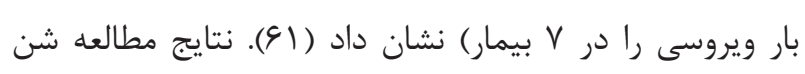
و همكار انش اثربخشى يلاسما درمانى را در ه بيمار (مرحله (Shen)

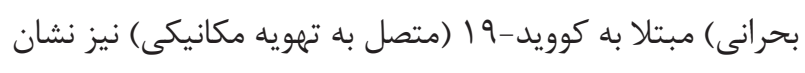

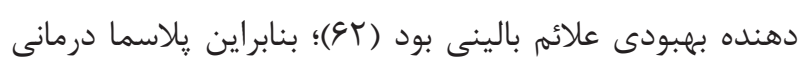
$r q \Delta \mid$

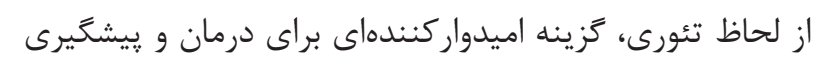

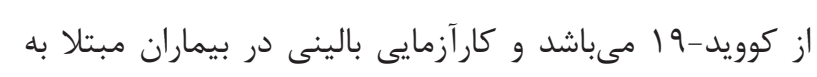

به دنبال كشف واكسن و دارويى براى ييشخيرى و درمان اين

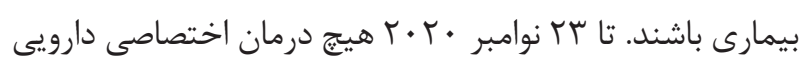

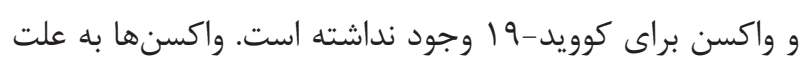
كاهش عوارض، مرى و مير و مقرون به صرفه بودن مؤثرترين

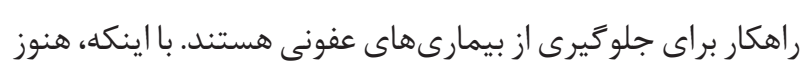

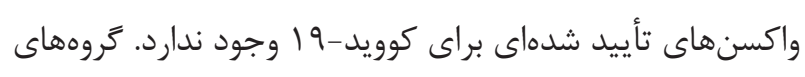
تحقيقاتى در سراسر جهان با استفاده از روشهاى مختى مختلف از جمله Recombinant protein ،Adenoviral vector ،DNA ،mRNA ييشرفت واكسن كوويد-9 19 را تسريع مى كنند (TV).

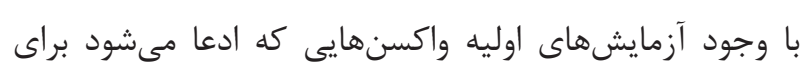

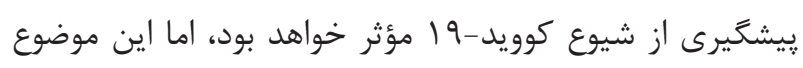
نيازمند آزمايشات بالينى و ارزيابى اطلاعات بالينى كوريد الينى توسط

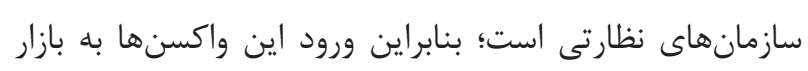

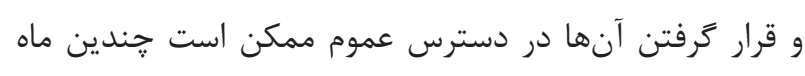

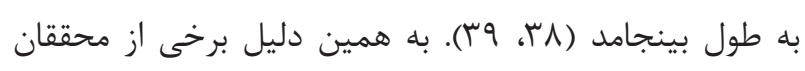
روى استفاده از داروهاى مؤثر در درمان كوويد-19 إم و يلاسما

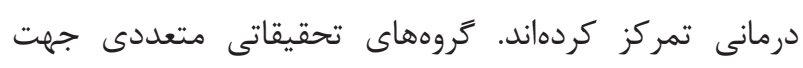

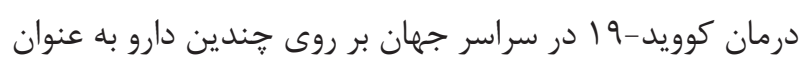

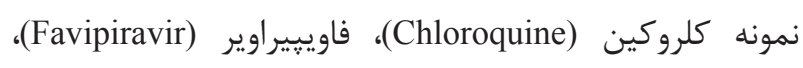

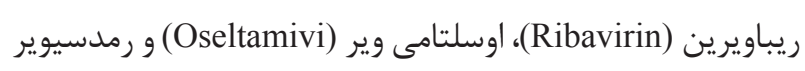

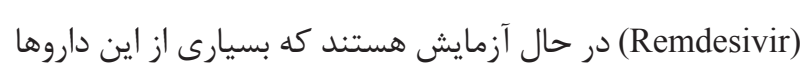

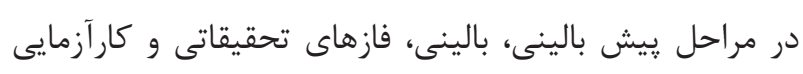

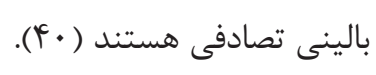

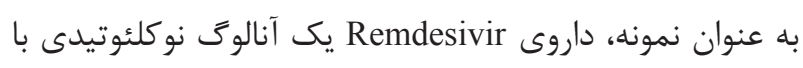

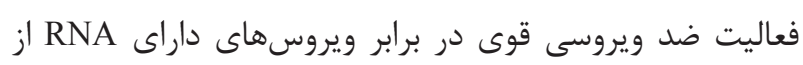

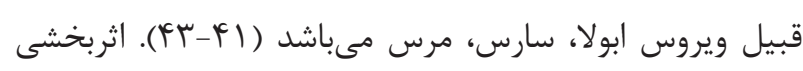

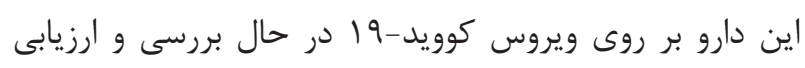
مىباشد. اين دارو در شرايط آزمايشعاهى و مطالعات حيوانى نتايج دوريج

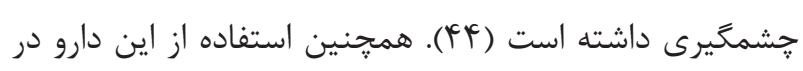

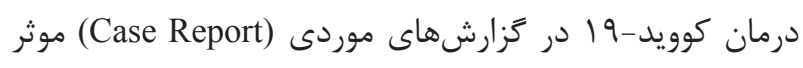

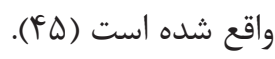
در حال حاضر رمدسيوير (Remdesivir) به عنوان اميدوار (مار).

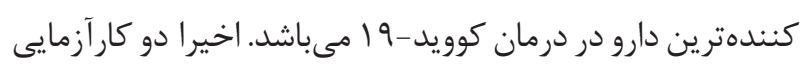

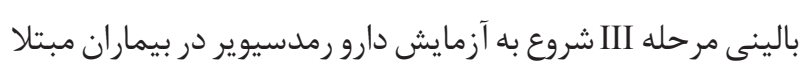


رعايت بهداشت تنفسى، :وشاندن دهان و بينى با آرنج يا

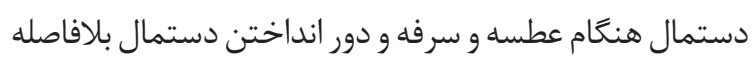
بعد از استفاده. در صورت احساس بيمارى و داشتن علائمى مانند تب، سرفه

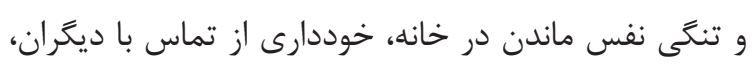

$$
\text { رعايت بهداشت فردى و اطلاع به مراكز درمانى. }
$$

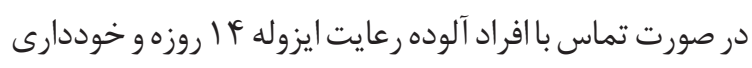
از تماس با ديكران، رعايت بهداشت فردى و اطلاع به مراكز

$$
\text { درمانى. }
$$

$$
\text { هرهيز از مسافرتهاى غيرضرورى. }
$$

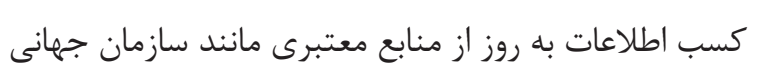

$$
\text { بهداشت و سايت وزارت بهداشت (F). }
$$

در يى شيوع گَترده ويروس كرونا در جهان، رعايت بهداشت

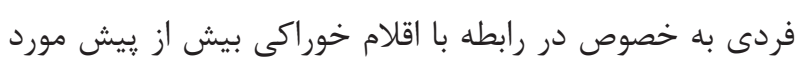
توجه قرار خرفته كه در زير اشاره شده است: شستشوى مرتب دستها قبل و بعد از دست زدن به به مواد غذايى استفاده از تركيب محلولهاى ضدعفونى كننده موجود در داروخانها در ضدعفونى كردن ميوهها و سبزيجات

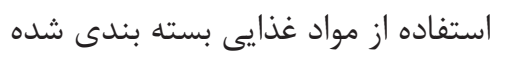

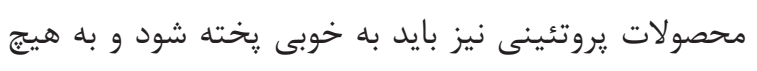

$$
\text { عنوان نيخته و نيم يز استفاده نشود. }
$$

كيسههاى حاوى ميوه و سبزيجات، نبايد با ساير وسايل منزل

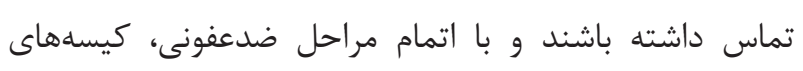

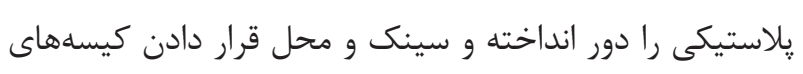

خريد را شسته يا ضد عفونى شود (ه) (\$).

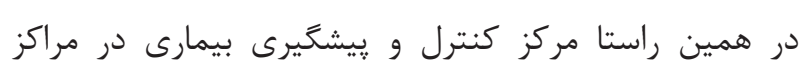
مراقبتهاى بهداشتى براى ييشخيرى و كنترل عفونت موارد زير را توصيه نموده است.

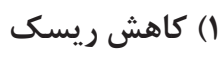

در مناطقى كه انتقال از طريق جامعه كسترده است، استراترىهاى رئي

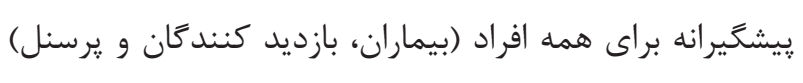

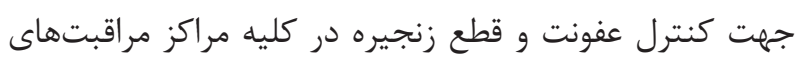

كوويد-19 آغاز شده است (4) (1). يروتكل درمانى وزارت بهداشت در آخرين نسخه (نسخه هشتم) بدين صورت است كه در افراد با علائم مراحل ابتدايى عفونت

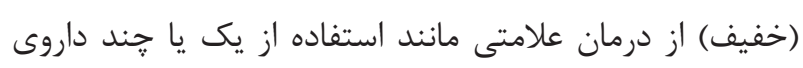
استامينوفن، نايروكسن، برم هكزين، دكسترومتورفان، ديفن ماند

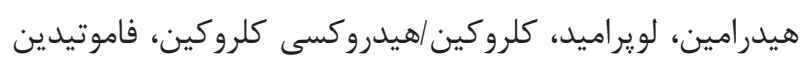

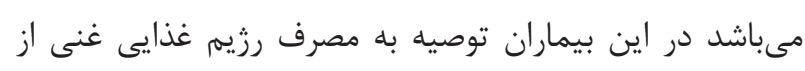

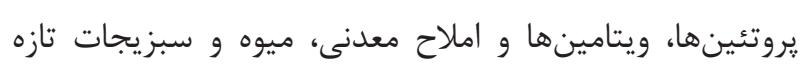

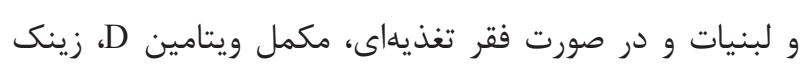

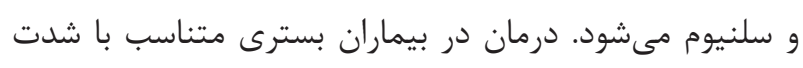

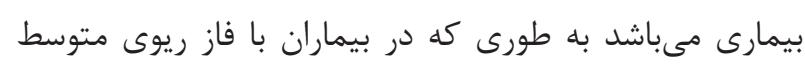

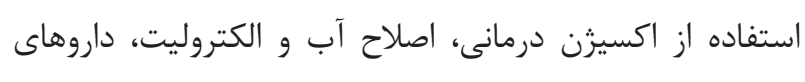

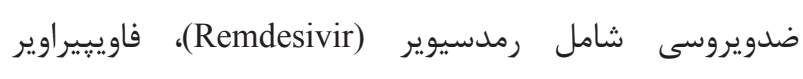

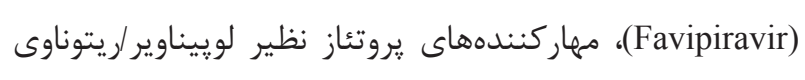
و و آتازاناوير (Lopinavir/ritonavir)

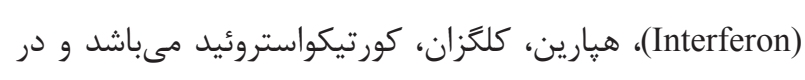
فاز شديد ريوى از دوزهاى بالاتر كورتون و پالسترايى استفاده

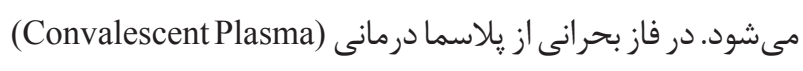

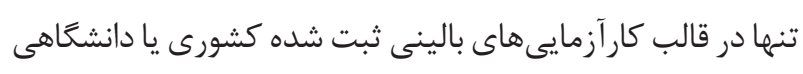

$$
\text { صورت مى گيرد (ساع). }
$$

\section{بيشگيرى و كنترل بيمارى كوويد-19}

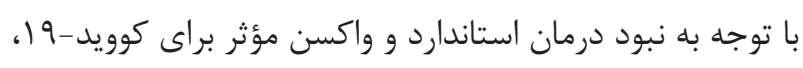
بهترين راه در شرايط حاضر كنترل عفونت و جلوكيرى از انتشار

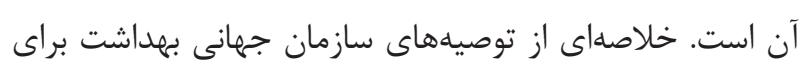

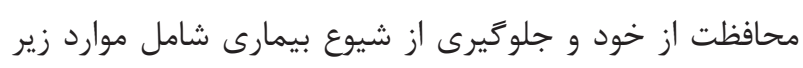
مى مباشد:

ماريت بهداشت فردى و يرهيز از تماس نزديك و مستقيم با

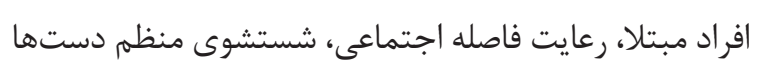

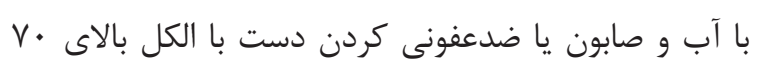
درصد. • استفاده از ماسك در محيطهاى شلوغ و با تهويه نامناسب. به

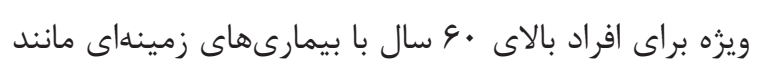

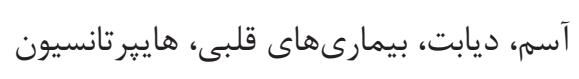




\section{بحث و نتيجهَيرى}

با توجه به موارد بيان شده در مقاله حاضر نظير همه گيرى جهانى

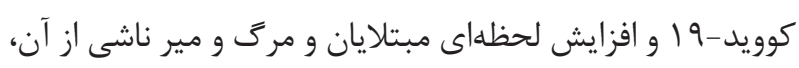
دارا بودن بستر رشد و انتشار سريع ويروس، نبود واكسن جهت

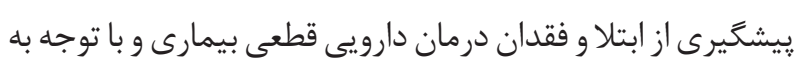
شروع فعاليتهاى اجتماعى در كشورمان بيشنهاد مىشود، سطح

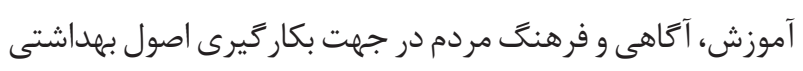
افزايش يابد و نظارت دقيق بر اجراى يروتكلهاى بهداشتى و روعايت

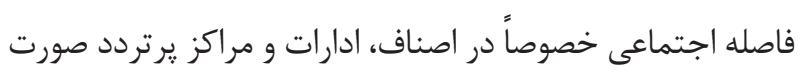
گ گيرد. گسترش و تقويت مطالعات علمى و يزوهشى و حمايت از مراكز موجود در زمينه ويروس كوويد-19 به منظور كاستن از خطرات و مهار كامل اين بيمارى انجام گيرد. در پايان قابل ذكر ذرين است كه تدوين و اجراى فورى برنامههاى جامع و زيربنايى جهت ييشخيرى و مديريت شيوع احتمالى كوويد-9 ا در شروع فصل ياييز ضرورتى انكار نايذير است.

$$
\text { تشكر و قدر دانى بن وسيله از همكارى و راهنمايى علمى كليه اساتيد و متخصصين. }
$$

\section{تضاد منافع}

بدين وسيله نويسندگان تصريح مىنمايند كه هيج گونه تضاد منافعى در خصوص يزوهش حاضر وجود ندارد.

\section{References}

1- Guo YR, Cao QD, Hong ZS, Tan YY, Chen SD, Jin HJ, et al. The origin, transmission and clinical therapies on coronavirus disease 2019 (COVID-19) outbreak - an update on the status. Mil Med Res. 2020; 7(1): 11. DOI: 10.1186/s40779-020-00240-0 PMID: 32169119

2- World Health Organization. Statement on the meeting of the International Health Regulations (2005) Emergency Committee regarding the outbreak of novel coronavirus (2019-nCoV) 2020 Available from: https://www.who.int/news/item/23-01-2020statement-on-the-meeting-of-the-international-health-regulations(2005)-emergency-committee-regarding-the-outbreak-of-novelcoronavirus-(2019-ncov).
بهداشتى ضرورت دارد كه ميزان مواجه بالقوه را كاهش دهند. با كاهش تعداد افرادى كه وارد يك مركز درمانى مىشوند (مثلاً لغو جراحىهاى انتخابى، استفاده از يزشكى از راه دور (ويزيتهاى

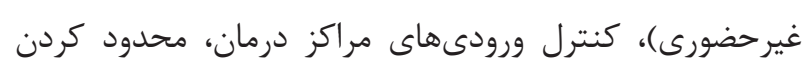

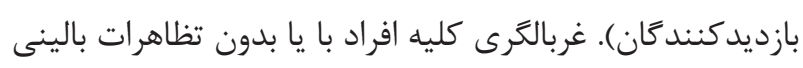

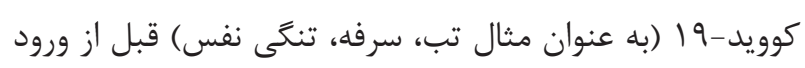
به مراكز بهداشتى و درمانى.

\section{r) جداسازى بيماران در اسرع وقت} فراهم كردن مناطق ترياز جداكانه با تهويه مناسب (در صورت

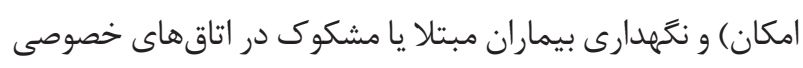
با درب بسته و حمام اختصاصى (در صورت امكان)، حمايت تنفسى مناسب (مانند CPR، لوله گذارى تراشه و تهويه غير تهاجمى) براى كنترل ياتوزنهاى منتقل شده از طريق مسير هوايى (در بيمارىهايى نظير كوويد-9 1، سل، سرخك، واريسلا)، كنترل عفونت محيطى با ضدعفونى اتاق بيمار بعد از تخليه مطابق استاندارد و دفع زبالههاى آلوده و آموزش به بيمار در مراقبت از خود.

$$
\begin{aligned}
& \text { r) محافظت از كاركنان مراقبتهاى بهداشتى }
\end{aligned}
$$

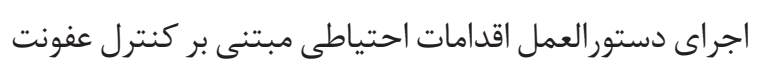

$$
\begin{aligned}
& \text { و قطع زنجيره }
\end{aligned}
$$

نصب موانع (شيشه يا پِنجره پِلاستيكى) براى محدود كردن تماس با بيماران در ترياز، محدود كردن تعداد كاركنان در

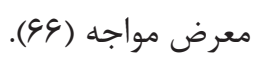

3- Maghded H, Ghafoor K, Sadiq A, Curran K, Rawat D, Rabie K. A Novel AI-enabled Framework to Diagnose Coronavirus COVID-19 using Smartphone Embedded Sensors: Design Study. 2020: 180-7. DOI: 10.1109/iri49571.2020.00033

4- Song Z, Xu Y, Bao L, Zhang L, Yu P, Qu Y, et al. From SARS to MERS, Thrusting Coronaviruses into the Spotlight. Viruses. 2019; 11(1). DOI: 10.3390/v11010059 PMID: 30646565

5- Chen Y, Liu Q, Guo D. Emerging coronaviruses: Genome structure, replication, and pathogenesis. J Med Virol. 2020; 92(4): 418-23. DOI: 10.1002/jmv.25681 PMID: 31967327

6- World meters. Coronavirus 2010 [Dec 05]. Available from: https:// www.worldometers.info/coronavirus/?fbclid=IwAR2b25vPdVVh 
ttps://www.worldometers.info/coronavirus.

7- Weiss S, Navas-Martin S. Coronavirus pathogenesis and the emerging pathogen severe acute respiratory syndrome coronavirus. Microbiol Mol Biol Rev. 2005; 69(4): 635-64. DOI: 10.1128/ MMBR.69.4.635-664.2005 PMID: 16339739

8- Sun P, Lu X, Xu C, Sun W, Pan B. Understanding of COVID-19 based on current evidence. J Med Virol. 2020; 92(6): 548-51. DOI: 10.1002/jmv.25722 PMID: 32096567

9- Ji W, Wang W, Zhao X, Zai J, Li X. Cross-species transmission of the newly identified coronavirus 2019-nCoV. J Med Virol. 2020; 92(4): 433-40. DOI: 10.1002/jmv.25682 PMID: 31967321

10- Li Q, Guan X, Wu P, Wang X, Zhou L, Tong Y, et al. Early Transmission Dynamics in Wuhan, China, of Novel CoronavirusInfected Pneumonia. N Engl J Med. 2020; 382(13): 1199-207. DOI: 10.1056/NEJMoa2001316 PMID: 31995857

11- Lu J, Cui J, Qian Z, Wang Y, Zhang H, Duan Y, et al. On the origin and continuing evolution of SARS-CoV-2. National Science Review. 2020;7(6):1012-23. DOI: 10.1093/nsr/nwaa036

12- Wang L, Wang Y, Ye D, Liu Q. Review of the 2019 novel coronavirus (SARS-CoV-2) based on current evidence. International J Antimicrobial Agents. 2020; 55(6): 105948. DOI: 10.1016/j.ijantimicag.2020.105948

13- Chan JF, Kok KH, Zhu Z, Chu H, To KK, Yuan S, et al. Genomic characterization of the 2019 novel human-pathogenic coronavirus isolated from a patient with atypical pneumonia after visiting Wuhan. Emerg Microbes Infect. 2020; 9(1): 221-36. DOI: 10.1080/22221751.2020.1719902 PMID: 31987001

14- Hoffmann M, Kleine-Weber H, Schroeder S, Kruger N, Herrler T, Erichsen S, et al. SARS-CoV-2 Cell Entry Depends on ACE2 and TMPRSS2 and Is Blocked by a Clinically Proven Protease Inhibitor. Cell. 2020; 181(2): 271-80 e8. DOI: 10.1016/j. cell.2020.02.052 PMID: 32142651

15- Liu Z, Xiao X, Wei X, Li J, Yang J, Tan H, et al. Composition and divergence of coronavirus spike proteins and host ACE2 receptors predict potential intermediate hosts of SARS-CoV-2. J Med Virol. 2020; 92(6): 595-601. DOI: 10.1002/jmv.25726 PMID: 32100877

16- Xu X, Chen P, Wang J, Feng J, Zhou H, Li X, et al. Evolution of the novel coronavirus from the ongoing Wuhan outbreak and modeling of its spike protein for risk of human transmission. Sci China Life Sci. 2020; 63(3): 457-60. DOI: 10.1007/s11427-0201637-5 PMID: 32009228

17- Zhang T, Wu Q, Zhang Z. Probable Pangolin Origin of SARSCoV-2 Associated with the COVID-19 Outbreak. Curr Biol. 2020; 30(7): 1346-51 e2. DOI: 10.1016/j.cub.2020.03.022 PMID: 32197085

18- Centers for Disease Control and Prevention. Symptoms of Coronavirus 2020 [Now 23]. Available from: https://www. cdc.gov/coronavirus/2019-ncov/symptoms-testing/symptoms. html?CDC_AA_refVal=https $\% 3 \mathrm{~A} \% 2 \mathrm{~F} \% 2 \mathrm{Fwww} . \mathrm{cdc}$. gov $\% 2$ Fcoronavirus $\% 2$ F 2019 -ncov $\% 2$ Fabout $\% 2$ Fsymptoms. html.

19- Wang D, Hu B, Hu C, Zhu F, Liu X, Zhang J, et al. Clinical
Characteristics of 138 Hospitalized Patients With 2019 Novel Coronavirus-Infected Pneumonia in Wuhan, China. JAMA. 2020; 323(11): 1061-9. DOI: 10.1001/jama.2020.1585 PMID: 32031570 20- Guan WJ, Ni ZY, Hu Y, Liang WH, Ou CQ, He JX, et al. Clinical Characteristics of Coronavirus Disease 2019 in China. N Engl J Med. 2020; 382(18): 1708-20. DOI: 10.1056/NEJMoa2002032 PMID: 32109013

21- Lu Q, Shi Y. Coronavirus disease (COVID-19) and neonate: What neonatologist need to know. J Med Virol. 2020; 92(6): 564-7. DOI: 10.1002/jmv.25740 PMID: 32115733

22- Lauer SA, Grantz KH, Bi Q, Jones FK, Zheng Q, Meredith $\mathrm{HR}$, et al. The Incubation Period of Coronavirus Disease 2019 (COVID-19) From Publicly Reported Confirmed Cases: Estimation and Application. Ann Intern Med. 2020; 172(9): $577-$ 82. DOI: 10.7326/M20-0504 PMID: 32150748

23- Chavez S, Long B, Koyfman A, Liang SY. Coronavirus Disease (COVID-19): A primer for emergency physicians. Am J Emerg Med. 2020. DOI: 10.1016/j.ajem.2020.03.036 PMID: 32265065

24- Van Doremalen N, Bushmaker T, Morris DH, Holbrook MG, Gamble A, Williamson BN, et al. Aerosol and Surface Stability of SARS-CoV-2 as Compared with SARS-CoV-1. N Engl J Med. 2020; 382(16): 1564-7. DOI: 10.1056/NEJMc2004973 PMID: 32182409

25- Schwartz DA. An Analysis of 38 Pregnant Women with COVID-19, Their Newborn Infants, and Maternal-Fetal Transmission of SARS-CoV-2: Maternal Coronavirus Infections and Pregnancy Outcomes. Arch Pathol Lab Med. 2020. DOI: 10.5858/arpa.20200901-SA PMID: 32180426

26- Wang W, Xu Y, Gao R, Lu R, Han K, Wu G, et al. Detection of SARS-CoV-2 in Different Types of Clinical Specimens. Jama. 2020. DOI: 10.1001/jama.2020.3786

27- Zhang W, Du RH, Li B, Zheng XS, Yang XL, Hu B, et al. Molecular and serological investigation of 2019-nCoV infected patients: implication of multiple shedding routes. Emerg Microbes Infect. 2020; 9(1): 386-9. DOI: 10.1080/22221751.2020.1729071 PMID: 32065057

28- World Health Organization. Report of the WHO-China Joint Mission on Coronavirus Disease 2019 (COVID-2019). 2020 [Now 23]. Available from: https://www.who.int/docs/default-source/ coronaviruse/who-china-joint-mission-on-covid-19-final-report. pdf.

29- Centers for Disease Control and Prevention. COVID-19 and Animals 2020 [Now 23]. Available from: https://www.cdc.gov/ coronavirus/2019-ncov/daily-life-coping/animals.html.

30- Wu Z, McGoogan JM. Characteristics of and Important Lessons From the Coronavirus Disease 2019 (COVID-19) Outbreak in China: Summary of a Report of 72314 Cases From the Chinese Center for Disease Control and Prevention. JAMA. 2020; 323(13): 1239-42. DOI: 10.1001/jama.2020.2648 PMID: 32091533

31- Samidurai A, Das A. Cardiovascular Complications Associated with COVID-19 and Potential Therapeutic $\sim$ Strategies. Int J Mol Sci. 2020; 21(18). DOI: 10.3390/ijms21186790 PMID: 32947927 
32- Ahmadian E, Hosseiniyan Khatibi SM, Razi Soofiyani S, Abediazar S, Shoja MM, Ardalan M, et al. Covid-19 and kidney injury: Pathophysiology and molecular mechanisms. Rev Med Virol. 2020:e2176. DOI: 10.1002/rmv.2176 PMID: 33022818

33- Chen N, Zhou M, Dong X, Qu J, Gong F, Han Y, et al. Epidemiological and clinical characteristics of 99 cases of 2019 novel coronavirus pneumonia in Wuhan, China: a descriptive study. The Lancet. 2020; 395(10223): 507-13. DOI: 10.1016/ s0140-6736(20)30211-7

34- Wong HYF, Lam HYS, Fong AH, Leung ST, Chin TW, Lo CSY, et al. Frequency and Distribution of Chest Radiographic Findings in Patients Positive for COVID-19. Radiology. 2020; 296(2): E72-E8. DOI: 10.1148/radiol.2020201160 PMID: 32216717

35- Ai T, Yang Z, Hou H, Zhan C, Chen C, Lv W, et al. Correlation of Chest CT and RT-PCR Testing for Coronavirus Disease 2019 (COVID-19) in China: A Report of 1014 Cases. Radiology. 2020; 296(2): E32-E40. DOI: 10.1148/radiol.2020200642 PMID: 32101510

36- Hou H, Wang T, Zhang B, Luo Y, Mao L, Wang F, et al. Detection of $\operatorname{IgM}$ and $\mathrm{IgG}$ antibodies in patients with coronavirus disease 2019. Clin Transl Immunology. 2020; 9(5): e01136. DOI: 10.1002/ cti2.1136 PMID: 32382418

37- Ahn DG, Shin HJ, Kim MH, Lee S, Kim HS, Myoung J, et al. Current Status of Epidemiology, Diagnosis, Therapeutics, and Vaccines for Novel Coronavirus Disease 2019 (COVID-19). J Microbiol Biotechnol. 2020; 30(3): 313-24. DOI: 10.4014/ jmb.2003.03011 PMID: 32238757

38- Ahmed SF, Quadeer AA, McKay MR. Preliminary Identification of Potential Vaccine Targets for the COVID-19 Coronavirus (SARS-CoV-2) Based on SARS-CoV Immunological Studies. Viruses. 2020; 12(3). DOI: 10.3390/v12030254 PMID:32106567

39- Immune responses in COVID-19 and potential vaccines: Lessons learned from SARS and MERS epidemic. Asian Pacific Journal of Allergy and Immunology. 2020. DOI: 10.12932/ap-200220-0772

40- Li G, De Clercq E. Therapeutic options for the 2019 novel coronavirus (2019-nCoV). Nat Rev Drug Discov. 2020; 19(3): 149-50. DOI: 10.1038/d41573-020-00016-0 PMID: 32127666

41- Mulangu S, Dodd LE, Davey RT, Jr., Tshiani Mbaya O, Proschan M, Mukadi D, et al. A Randomized, Controlled Trial of Ebola Virus Disease Therapeutics. N Engl J Med. 2019; 381(24): 2293303. DOI: 10.1056/NEJMoa1910993 PMID: 31774950

42- Brown AJ, Won JJ, Graham RL, Dinnon KH, 3rd, Sims AC, Feng $J Y$, et al. Broad spectrum antiviral remdesivir inhibits human endemic and zoonotic deltacoronaviruses with a highly divergent RNA dependent RNA polymerase. Antiviral Res. 2019; 169: 104541. DOI: 10.1016/j.antiviral.2019.104541 PMID: 31233808

43- Sheahan TP, Sims AC, Leist SR, Schafer A, Won J, Brown AJ, et al. Comparative therapeutic efficacy of remdesivir and combination lopinavir, ritonavir, and interferon beta against MERS-CoV. Nat Commun. 2020; 11(1): 222. DOI: 10.1038/s41466-13940-019-7 PMID: 31924756 and chloroquine effectively inhibit the recently emerged novel coronavirus (2019-nCoV) in vitro. Cell Res. 2020; 30(3): 269-71. DOI: 10.1038/s41422-020-0282-0 PMID: 32020029

45- Holshue ML, DeBolt C, Lindquist S, Lofy KH, Wiesman J, Bruce H, et al. First Case of 2019 Novel Coronavirus in the United States. N Engl J Med. 2020; 382(10): 929-36. DOI: 10.1056/ NEJMoa2001191 PMID: 32004427

46- Zhai P, Ding Y, Wu X, Long J, Zhong Y, Li Y. The epidemiology, diagnosis and treatment of COVID-19. Int J Antimicrob Agents. 2020; 55(5): 105955. DOI: 10.1016/j.ijantimicag.2020.105955 PMID: 32234468

47- Liu C, Zhou Q, Li Y, Garner LV, Watkins SP, Carter LJ, et al. Research and Development on Therapeutic Agents and Vaccines for COVID-19 and Related Human Coronavirus Diseases. ACS Cent Sci. 2020; 6(3): 315-31. DOI: 10.1021/acscentsci.0c00272 PMID: 32226821

48- Gao J, Tian Z, Yang X. Breakthrough: Chloroquine phosphate has shown apparent efficacy in treatment of COVID-19 associated pneumonia in clinical studies. Biosci Trends. 2020;14(1):72-3. DOI: 10.5582/bst.2020.01047 PMID: 32074550

49- McCreary EK, Pogue JM. Coronavirus Disease 2019 Treatment: A Review of Early and Emerging Options. Open Forum Infect Dis. 2020; 7(4): Ofaa105. DOI: 10.1093/ofid/ofaa105 PMID: 32284951

50- Dong L, Hu S, Gao J. Discovering drugs to treat coronavirus disease 2019 (COVID-19). Drug Discov Ther. 2020; 14(1): 58-60. DOI: 10.5582/ddt.2020.01012 PMID: 32147628

51- Wang Z, Chen X, Lu Y, Chen F, Zhang W. Clinical characteristics and therapeutic procedure for four cases with 2019 novel coronavirus pneumonia receiving combined Chinese and Western medicine treatment. Biosci Trends. 2020; 14(1): 64-8. DOI: 10.5582/bst.2020.01030 PMID: 32037389

52- Alhazzani W, Moller MH, Arabi YM, Loeb M, Gong MN, Fan E, et al. Surviving Sepsis Campaign: guidelines on the management of critically ill adults with Coronavirus Disease 2019 (COVID-19). Intensive Care Med. 2020; 46(5): 854-87. DOI: 10.1007/s00134020-06022-5 PMID: 32222812

53- Cao B, Wang Y, Wen D, Liu W, Wang J, Fan G, et al. A Trial of Lopinavir-Ritonavir in Adults Hospitalized with Severe Covid-19. N Engl J Med. 2020; 382(19): 1787-99. DOI: 10.1056/ NEJMoa2001282 PMID: 32187464

54- Zheng J. SARS-CoV-2: an Emerging Coronavirus that Causes a Global Threat. Int J Biol Sci. 2020; 16(10): 1678-85. DOI: 10.7150/ijbs.45053 PMID: 32226285

55- Chen L, Xiong J, Bao L, Shi Y. Convalescent plasma as a potential therapy for COVID-19. The Lancet Infectious Diseases. 2020; 20(4): 398-400. DOI: 10.1016/s1473-3099(20)30141-9

56- Mehta N, Mazer-Amirshahi M, Alkindi N, Pourmand A. Pharmacotherapy in COVID-19; A narrative review for emergency providers. Am J Emerg Med. 2020;38(7):1488-93. DOI: 10.1016/j. ajem.2020.04.035 PMID: 32336586

57- Zhou B, Zhong N, Guan Y. Treatment with convalescent plasma 
for influenza A (H5N1) infection. N Engl J Med. 2007; 357(14): 1450-1. DOI: 10.1056/NEJMc070359 PMID: 17914053

58- Hung IF, To KK, Lee CK, Lee KL, Chan K, Yan WW, et al. Convalescent plasma treatment reduced mortality in patients with severe pandemic influenza A (H1N1) 2009 virus infection. Clin Infect Dis. 2011; 52(4): 447-56. DOI: 10.1093/cid/ciq106 PMID: 21248066

59- Wong SS, Yuen KY. The management of coronavirus infections with particular reference to SARS. J Antimicrob Chemother. 2008; 62(3): 437-41. DOI: 10.1093/jac/dkn243 PMID: 18565970

60- Mair-Jenkins J, Saavedra-Campos M, Baillie JK, Cleary P, Khaw FM, Lim WS, et al. The effectiveness of convalescent plasma and hyperimmune immunoglobulin for the treatment of severe acute respiratory infections of viral etiology: a systematic review and exploratory meta-analysis. J Infect Dis. 2015; 211(1): 80-90. DOI: 10.1093/infdis/jiu396 PMID: 25030060

61- Duan K, Liu B, Li C, Zhang H, Yu T, Qu J, et al. Effectiveness of convalescent plasma therapy in severe COVID-19 patients. Proc Natl Acad Sci U S A. 2020; 117(17): 9490-6. DOI: 10.1073/ pnas.2004168117 PMID: 32253318
62- Shen C, Wang Z, Zhao F, Yang Y, Li J, Yuan J, et al. Treatment of 5 Critically Ill Patients With COVID-19 With Convalescent Plasma. JAMA. 2020; 323(16): 1582-9. DOI: 10.1001/jama.2020.4783 PMID: 32219428

63- Ministry of Health and Medical Education. Coveid Diagnosis and Treatment Guide - 19 in Outpatient and Inpatient Service Levels 2020. Eighth Edition:[

64- World Health Organization. Coronavirus disease (COVID-19) advice for the public 2020 [Now 23]. Available from: https://www. who.int/emergencies/diseases/novel-coronavirus-2019/advicefor-public.

65- Unicef for every child. 2020 [Now 23]. Available from: https:// www.unicef.org/iran/.

66- Centers for Disease Control and Prevention. Infection Control Guidance. Interim Infection Prevention and Control Recommendations for Patients with Suspected or Confirmed Coronavirus Disease 2019 (COVID-19) in Healthcare Settings 2020 [Now 23]. Available from: https://www.cdc.gov/ coronavirus/2019-ncov/hcp/infection-control-recommendations. html. 